\title{
Toward modeling the social edition: An approach to understanding the electronic scholarly edition in the context of new and emerging social media*
}

\author{
Ray Siemens \\ Electronic Textual Cultures Lab, University of Victoria \\ Meagan Timney \\ Blurb, Inc. \\ Cara Leitch \\ Department of English, University of Victoria \\ Corina Koolen \\ Centre for the Arts in Society, Leiden University

\begin{abstract}
Alex Garnett
British Columbia

with the ETCL, INKE, and PKP Research Groups
\end{abstract} \\ School of Library, Archival \& Information Studies, University of
}

\begin{abstract}
* Earlier versions of this work were presented by Leitch, Timney, and Siemens, variously, in 2010 and 2011 to groups at gatherings of the Modern Language Association (Los Angeles), Digital Humanities (Stanford University), the Institute for English Studies (London), the Renaissance Society of America (Montreal), Archives and the Profession (University of Texas Austin), Congress of the Humanities and Social Science Federation of Canada (Concordia University), Huygens Institute (The Hague), University of Victoria, and elsewhere. An earlier version of this piece was made available via the Electronic Textual Cultures Lab (ETCL) website, at http://etcl.uvic.ca/files/2011/01/ timneyleitchsiemens-socialedition.pdf, under the title 'Opening the Gates: A New Model for Edition Production in a Time of Collaboration;' it was also circulated at the Society for Textual Studies' 2011 meeting in a seminar led by Katherine D Harris, 'Redefining the Scholarly Edition'.

In addition to benefiting greatly from discussion with those via these forums, and from comments of $L L C$ 's anonymous reviewers, at its core this article results from the combined consideration and work of a number of researchers across several research groups-including members of the ETCL, the Implementing New Knowledge Environments (INKE) project, and the Public Knowledge Project (PKP), with writing up to the earlier-circulated draft (as above) coordinated chiefly by Timney. The phrase 'social edition' was, to our knowledge, coined by Leitch, describing aspects of the phenomena reflected on in this paper article our group was discussing in 2009. Final coordination, writing, and revision of this paper article were carried out by Siemens, with the assistance of Garnett, Koolen, and others from the research groups credited.
\end{abstract}


Correspondence:

Ray Siemens,

Electronic Textual Cultures Laboratory, c/o Humanities Computing and Media Centre, University of Victoria, PO Box 1700, STN CSC, Victoria, BC V8W 2Y2, Canada.

E-mail: siemens@uvic.ca

\section{Abstract}

This article explores building blocks in extant and emerging social media toward the possibilities they offer to the scholarly edition in electronic form, positing that we are witnessing the nascent stages of a new 'social' edition existing at the intersection of social media and digital editing. Beginning with a typological formulation of electronic scholarly editions, activities common to humanities scholars who engage with texts as expert readers are considered, noting that many methods of engagement both reflect the interrelated nature of long-standing professional reading strategies and are social in nature; extending this frame work, the next steps in the scholarly edition's development in its incorporation of social media functionality reflect the importance of traditional humanistic activities and workflows, and include collaboration, incorporating contributions by its readers and re-visioning the role of the editor away from that of ultimate authority and more toward that of facilitator of reader involvement. Intended to provide a 'toolkit' for academic consideration, this discussion of the emerging social edition points to new methods of textual engagement in digital literary studies and is accompanied by two integral, detailed appendices, published in Digital Humanities Quarterly under the title 'Pertinent discussions toward modeling the social edition: Annotated bibliographies' (http:// www.digitalhumanities.org/dhq/vol/6/1/000111/000111.html): one addressing issues pertinent to online reading and interaction, and another on social networking tools.

\section{Introduction: Extending Electronic Editorial Traditions}

In the very early days of the World Wide Web, but well into a period in which our community understood the positive and transformative impact that computational technique has had on scholarly editing, Fortier (1991) reminded us that literary studies are, and always have been, focused on engagement with texts regardless of interpretive theoretical predisposition. In digital literary studies, that textual focus manifests in a number of theories about the nature of the text in general and the electronic scholarly edition in particular, and has developed to the point that we can begin to construct, in a relatively straightforward manner, a basic typology of electronic scholarly editions via the approach each type takes in handling and engaging with its textual materials: from edited electronic text plus analytical tools for its readers (dynamic text), to text plus a static set of additional supporting materials in digital form for reader navigation and subsequent analysis (hypertextual edition), to text augmented by both dynamic analytical means and hypertextually-linked access to fixed resources plus automated means of discovering and interrelating external resources (dynamic edition). Such a typology, reductive as it may be, allows us to look forward-as McGann (2001), Bryant (2002), Shillingsburg (2006), Gabler (2010), Robinson (2010), and many others (as well as those mentioned, beyond specific citation) have encouraged us to do variously ${ }^{1}$ - to what lies ahead in our treatment of the texts, and the textual editions, that sit at the core of our contemplation in literary studies and similar disciplines.

Well into what is often called the 'new' age of the internet-becoming immersed as we are in a generation of online tools facilitating collaboration, information sharing, and interoperability; becoming immersed as we are by social media interaction on the web-it is worth noting that the types of electronic scholarly editions we see prominently today were largely developed before the ubiquity of the web that we now enjoy, and do not accurately reflect the full range of useful 
possibilities present for academic engagement and interaction around the textual materials that are our focus. While the electronic medium is most certainly a productive space in which to present and analyze editions, it is increasingly difficult to ignore the influence of new and emerging possibilities for the electronic scholarly edition in the current phase in the social formation of the web. As such, our understanding of the electronic scholarly edition in its current form requires reconsideration in light of the collaborative potential of already extant and newly emerging digital technologies; put another way, we need to extend our understanding of the scholarly edition in light of new models of edition production that embrace social networking and its commensurate tools. Toward understanding the scholarly edition in the context of new and emerging social media, this article and its related appendices (published in Digital Humanities Quarterly) offer an early engagement of pertinent issues and, ultimately, a utility-based consideration in an academic context of the toolkit that allows us to consider the 'social' edition as an extension of the traditions in which it is situated and in which it has the potential to inform productively.

\section{A Rough Typology of the Scholarly Electronic Edition}

Historically, the scholarly edition relied on the print medium and the expertise of a single authority or editor at its helm-something almost immediately challenged by the provision of text in electronic, readily malleable, and ultimately re-combinable and redistributable form (as it was challenged in print by some as well). One of the first models of the movement from the print to the electronic edition is typically referred to as the 'dynamic text'. Its principles articulated most fully in the late 1980s, the dynamic text emphasizes extant textual and linguistic relationships; its historical roots are in word-based scholarly activities such as concordance creation and indexing, collation, collocation and distribution, attribution and dating, and rhyme and content analysis, while allowing the reader to engage with the text 'dynamically' (Siemens, 2005). In practical terms, this model of the electronic edition is the combination of a properly encoded electronic text with text-retrieval and analysis software (Lancashire, 1989). What makes this type of edition 'dynamic' is the way in which the computer facilitates a non-linear interaction with the text. In essence, the dynamic edition structures and treats the text as a database. This database structure allows the reader to explore a good deal of text-based information that is not as easily accessible to the reader of the same work in print. In addition to its disseminative and editorial flexibility, a chief benefit of this sort of edition is that it combines text with tools, speeding academic reading-related tasks. The dynamic text automates reading-related functions that would likely not be carried out without the assistance of the computer because of the expense in time involved. A 'computer-assisted analysis' of the text and a linear 'reading' of it are acts that become closely affiliated and, potentially, equivalent.

Following quickly, with the rise of hypertext, the 'hypertextual edition'2 exploits the ability of hypertextual organization to facilitate a reader's interaction with the apparatus (textual, critical, and otherwise) that traditionally accompanies scholarly editions, as well as with relevant external textual and graphical resources, critical materials, and so forth (Faulhaber, 1991); it is seen by some as a technological manifestation of the social theories of editing that were transformative near the end of the last century. As with the dynamic text, all of the interactions facilitated by a hypertextual edition could be carried out, hypothetically, with a print edition; here, however, that edition would have to be supplemented by the resources (paper-based, audio, video) of an excellent library and considerable leg-work. What is hypothetically available to the reader in a research library, or group of libraries, is here made immediately available, encouraging use of the resources by the reader in a seamless fashion; as such, the hypertextual edition, like the dynamic text, also makes accessible dimensions of the text not normally or conveniently available to readers, but does so by providing immediate access to a different sort of material than that handled by the dynamic text. Moreover, as with the dynamic text, 
the hypertextual edition affords a type of intertextuality that produces a critical reader with a potentially more powerful grasp of that which is being read than one employing print resources alone. Lastly, because of the broad range of materials that can be incorporated therein, both because of the economy of data storage in the electronic medium and the benefits of hypertextual navigation, the hypertextual edition can quite comfortably accommodate many 'types' of editions: documentary, genealogical, copy-text, multiple version, sociallybased, eclectic, variorum, and so forth.

In his seminal discussion of the hypertextual edition, Faulhaber (1991) saw the hypertextual edition as having evolved from the dynamic text (see also Neuman, 1991). In practice, however, hypertextual editions often relegate the principles of the dynamic edition to the background (if they are included at all), ${ }^{3}$ and instead emphasize the ability of hypertext to provide interaction with materials common to, or ideal for, print-based editions-albeit, with much greater ease-of-navigation and with the potential for interaction with a much larger body of material than that which typically accompanies a paper edition.

As such, the hypertextual edition is most often embraced for its employment of hypertext to emphasize textual and extra-textual relationships, facilitating the reader's interaction with the text and materials related to it with an ease unknown even in the best of scholarly editions published in print; its historical roots are to be found in the apparatuses of scholarly editions and, in the best of examples, the variorum editions. The hypertextual edition, as well, facilitates a close affiliation of the acts of reading and analysis by providing and assisting in the management of a significant amount of related material additional to the text of the edition itself; promoting such an affiliation of reading and analysis is in keeping with the goals of all scholarly editions, electronic and otherwise (Lavagnino 1995), and the tools that a hypertextual edition can provide are significant (Cover, 1990).

Moving forward, the argument towards the 'dynamic edition' is founded, first, in the observation that the two perspectives on the electronic scholarly edition, dynamic and hypertextual, should be united in practice as they are, seemingly, in theory so that the reader can take advantage of both dynamic interaction with the text 'and' its related materials, and also reap the benefits of the fixed hypertextual links that typify the standard relation of materials we find in a scholarly edition. It is then augmented by the notion that even these types of editions, like their print counterparts in many ways, are objects that attempt to represent or fix, at a single moment in time, the work of an unfixed, ever-evolving - and thus dynamic - scholarly community engaged in the process of stockpiling scholarship, as Frye (1991) might note. As the argument goes: electronic editions that live up to the potential of the medium, especially in terms of the inclusivity that it allows, must also be 'dynamic'; they must be able to navigate the contents of the edition in familiar ways, and also able to reflect and draw upon the growing, evolving, and unfixed stockpile of scholarship that relates to the matter of the edition. ${ }^{4}$ The dynamic edition, of which there is not yet an exemplifying touchstone, is predicated on the possibility that the level of interaction one can enjoy with an electronic edition itself, if facilitated in the style of the dynamic text, can replace much of the interaction that one typically has with a text's accompanying materials via explicit hypertextual links in a hypertextual edition. The principles of computationally facilitated interaction allowed by the dynamic text, which indexes and concords itself, are transferrable to the realm of textual apparatus and commentary as typically modeled in the hypertextual edition, and well beyond into all materials in the medium that relate to the matter of any edition. Such an edition has the ability, in effect, to annotate itself and provide its own apparatus, employing sophisticated software to automate the process of formalizing the associations we take for granted in current editions. ${ }^{5}$

In this, we capitalize on a growing ability to manage, and to navigate, what is available in relation to our electronic scholarly editions in a dynamic manner. ${ }^{6}$ The premise for this navigation is found in humanistic assumptions of the relations that exist within and among texts; it rises out of an accepted understanding of intertextuality, explicitly manifest. A hypertext, which in its best definition is a 'multisequentially read text' (Landow, 
1999), embraces such an understanding, and implementations of hypertextual structures rely on the fact that one instance of textual material has association with other instances; in short, such structures rely on the fact that intertextuality exists, and that their advancement, further, can be managed by varied means, including algorithmic. At base, we might see in this a connection to the founding functional premises of socially facilitated interaction on the web-a useful point of derivation to consider.

\section{Some Pertinent Activities of the Humanist, in the Context of the Commons}

Just as the textual core of the literary-based scholar's activity has remained fairly stable over time-even as the ways in which the scholar may access and interact with that core have changed considerable-the core of activities traditionally undertaken by humanities scholarship have altered very little since the professionalization of academic study during the nineteenth century. Recent work toward articulating them and even modeling them computationally, as independent basic activities or in clusters of related activities, has been a valuable occupation of the digital humanities community, especially among those who build computational tools for humanistic use; ${ }^{7}$ much of this work is situated around key activities of humanities scholars as described by Unsworth (2000) among the seven scholarly primitives essential to humanistic work: discovering, annotating, comparing, referring, sampling, illustrating, and representing.

Not surprisingly, from their earliest examples digital scholarly editions have aspects of their functional interaction modeled to facilitate these activities, typically in the context of what might best be described as a computationally modeled humanistic workflow. Elsewhere, in a piece entitled 'Underpinnings of the Social Edition' (Siemens et al., 2010) that reported on work carried up to $c a 2008$ on a prototypical reading environment in a subjectspecific knowledgebase, members of our research team explored the activities of the humanist via the output of humanistic achievement toward identifying exemplary, interrelated groups of tasks for the computational model we would build to understand them better: the 'representation' of archival materials; 'analysis' or critical inquiry originating in those materials; and the 'communication' of the results of these tasks. ${ }^{8}$ Articulated initially in 2004, the computational model was built by 2007 or so and, as reported at the conference The Shape of Things to Come (University of Virginia, 2010), this work was stalled $c a 2008$ with the realization-after we brought our computational model to some of the same expert, professional readers in the user groups with whom we had consulted initially in the formulation of our model (itself reported, partly, in Siemens et al. 2009) — that expert readers in our discipline were beginning to incorporate social media tools, seemingly as they emerged, in their standard activities without explicit identification of them as such, seeing them as natural extensions of the way in which they had always carried out their work. This represented a significant departure from the earlier explicitly articulated practices on which our model was established; that such activity had not been hitherto documented was surprising, and yet proof of such a movement was then readily found in the widespread acceptance of tools such as Zotero. Subsequent discussion suggested that such tools used by expert readers were related, chiefly, to activities in areas of analysis, synthesis, communication, and formal dissemination-each with the potential to be, by their nature, both interrelated and social to varying degrees, some of which can be dictated by the scholar: for example, analysis and synthesis grow from communication that, in turn, affects formal dissemination, and communication and dissemination cannot take place without what is generated by synthesis and analysis; and, noted also was that, just as analysis and synthesis tools in use by our community draw us closer to the objects of our contemplation, so too do communicative and disseminative tools draw us closer to each other and to the communities we serve beyond academe.

Derived from study of expert readers in our discipline, as above, this movement is also documented in terms of literary theory and those of community; 
two evolving concepts are central to this: the social dimension of McGann's model of multidimensional textuality and the idea of the community of practice, broadly construed. In 'Marking Texts of Many Directions', McGann outlines a key dimension of textuality as 'social', which is production- and reception-oriented (2004, p. 214) ${ }^{9}$-an area in which digital textual modeling and mediation is noted to have, at the time, been least successful. Here, we see the social dimension of reading and analysis identified implicitly for broadening via computational facilitation, a notion extended further, and in broader context, when McGann notes in the context of humanistic labour and engagement that 'There are crowds of us yet to be sourced' (2010).

These crowds exist in large part in communities of practice situated around humanistic methods and materials. The term 'community of practice' refers to a group that forms around a particular interest, where individual members participate in collaborative activities of various kinds. Active involvement in the group is key; through this involvement, group members 'develop a shared repertoire of resources: experiences, stories, tools, ways of addressing recurring problems-in short a shared practice'. ${ }^{10}$ Knowledge-building communities, as a particular kind of community of practice, take 'as an explicit goal the development of individual and collective understanding' (Hoadley and Kilner, 2005, p. 33). In academe, we have noted communities of practice via varied names, and have described such large and now well-established initiatives as the Text Encoding Initiative-and even humanities computing and the digital humanities, earlier-in these terms; indeed, the digital humanities readily understand such collaborative formations (Inman et al., 2004). With the facilitation of social media, there is a growing movement in humanities knowledgebuilding communities to expand the scope of community membership beyond academics, and into the interested and engaged general public, to those practicing what has come to be termed citizen scholarship. Greenberg (2010) identifies three modes of citizen scholarship-contributory, collaborative, and co-created-in each, the traditional scholarly community of practice is extended to include public expertise while still valuing the experience, resources, and tools already in place; based on experience with humanities projects that have had extra-academic appeal and active engagement, many in our community have highlighted ways in which digital scholarship can welcome the contributions of participants from outside academe, via means of control and regulation that are not wholly foreign to processes used by humanists traditionally. ${ }^{11}$ The key to success in this instance is being very clear in our understanding of what it is we do, how we do it, and how we evaluate the results of what we have done across our pertinent activities, ${ }^{12}$ regardless of how we articulate, group, and model those activities.

\section{The General Scope of Social Software Applicable to the Scholarly Edition}

Within this framework, then, it is worth considering what is of most use to the scholarly edition from among the abundance of interactive digital tools with which scholars may choose to engage, and that might augment and enable communities of practice as they may exist around the texts that lie at the core of our consideration-tools, both scholarly and non-scholarly, that facilitate the sharing of and interaction with data in various ways, and offer new possibilities for community-driven scholarship. The majority of these tools fall into the broad category of 'social software', which is, noted Boyd (2006), 'based on supporting the desire of individuals to affiliate, their desire to be pulled into groups to achieve their personal goals'. At core, social software comes in many kinds, often grouped based on the nature of their interaction with (and with others interacting with) digital objects: knowledge creation and sharing, media sharing, blogs, bibliographic and bookmarking tools, aggregators, collaborative (scholarly) editing, massively multi-player online games (MMOGs), peer to peer social networks, project management software, and wide-scope content management systems, among others.

While useful to consider social software within these many and broad divisions, it is most 
productive in the context of this article to focus more specifically on those most readily applicable to the pursuit of the next steps of the scholarly edition. Here, issues of device and interaction platform arise, ${ }^{13}$ as do those around commenting and annotation, collaborative reading and learning, ${ }^{14}$ referencing and citation systems, peer review and identity, ${ }^{15}$ and patterns of use specific to academic use of social media and the scholarly use of social media by those in communities beyond academe, ${ }^{16}$ and, above all, collaboration; ${ }^{17}$ these are treated in great detail, with a survey of the emerging professional literature in the area, in the related appendices (published in Digital Humanities Quarterly), the first entitled 'Reading Devices, Tools and Social Media Issues of Pertinence to the Development of the Scholarly Edition' (Koolen and Garnett) and the second entitled 'Social Networking Tools for Professional Readers in the Humanities' (Leitch). They are organized according to their relevance to their use in relation to the 'social' edition, emphasizing the crucial features of these tools and the ways in which they engender new modes of engagement with digital objects, such as (1) collaborative annotation, (2) user-derived content, (3) folksonomy tagging, (4) community bibliography, and (5) shared text analysis. What follows is an overview of some of the current possibilities in each category:

(1) Collaborative Annotation: A chief scholarly primitive, annotation is crucial to scholarly editorial activities. While older models privilege the annotations of a single editor, social tools such as BioNotate (http://bionotate .sourceforge.net), Google Wave (http://wave .google.com), digress.it (http://digress.it; formerly CommentPress), Reframe it (http:// reframeit.com), and Diigo (http://www.diigo .com) allow for community knowledge creation. These collaborative systems usually require the installation of a toolbar that allows for annotation layering to promote 'the incremental growth of information as users review others' thoughts on a resource before adding their own' (Educause). Diigo, which markets itself as a 'group knowledge repository', serves as a prime example here, as it comprises the key features of annotation: highlighting and markup (known as sticky notes), as well as searchable tags and bookmarks. In this context, see also, among others, Marshall (1997), Ovsiannikov et al. (1999), Cadiz and Grudin (2000), Wolfe (2002), Lardinois (2009), Hunter et al. (2010), Watters (2011), and Yang (2011).

(2) User-derived Content: Some online repositories allow for the creation of user-derived content, or the collection and management of fully searchable exhibits comprising multiple digital objects. The opportunity for collaborative knowledge building is most prevalent in sites that already contain large-scale collections, as the exhibits are by necessity limited by the scope of the material available. Some prime examples include the Library of Congress's Flickr Stream (http:// www.flickr.com/photos/library_of_congress/), Inexhibit (http://www.indexhibit.org/), and the Networked Infrastructure for NineteenthCentury Electronic Scholarship (NINES) Collex (http://www.nines.org). In this context, see also, among many others, Fitzpatrick (2007), Hopkins (2010), Fernheimer et al. (2011), Howard (2011), and Kjellber (2010).

(3) Folksonomy Tagging: Collaborative or social tagging is 'the process by which many users add metadata in the form of keywords to shared content' (Golder and Huberman, 2006). The term now most often used to describe this type of user-generated cataloguing is 'folksonomy', which is defined as 'the result of personal free tagging of information and objects [...] for one's own retrieval. The tagging is done in a social environment (usually shared and open to others). Folksonomy is created from the act of tagging by the person consuming the information' (Vander Wal, 2007). The English Broadside Ballad Archive (http://emc.english.ucsb.edu/ ballad_project) uses a type of 'user-generated metadata' (Mathes, 2004) to manage and catalog images. Other applications that manage knowledge using folksonomy include many media sharing sites such as Flickr 
(http://flickr.com; see Fig. 1), and Twitter (http://twitter.com), bookmarking sites such as Del.icio.us, as well as Diigo (above). See also Guy and Tonkin (2006).

(4) Community Bibliography: Social bibliographies relate closely to collaborative tagging and also participate in knowledge creation. These tools allow users to collect and catalog references and resources using academic citations, folksonomy tagging, and link sharing. Some of the most popular community bibliography tools include Zotero (http://www .zotero.org; see also Cohen, 2008), Digg (http://digg.com), reddit (http://www.reddit .com), StumbleUpon (http://www.stumble upon.com), Connotea (http://www.connotea .org), CiteULike (http://www.citeulike.org), and BibSonomy (http://www.bibsonomy .org). BibSonomy, for example, is a 'social bookmark and publication sharing system'. Twitter (http://www.twitter.com) has also allowed groups of users to share links and resources, especially within the digital humanities community (see Priem and Costello, 2010 and Ross et al. 2011 for other academic uses). See also Hendry et al. (2006) and, for social bookmarking, Estelles et al. (2010), Hammond et al. (2005), and Lund et al. (2005).

(5) Text-Analysis: Digital humanities textual analysis involves the application of algorithmically facilitated search, retrieval, and critical processes that, originating in humanitiesbased work, have been demonstrated to have application far beyond' (Schriebman et al. 2004, vii). Examples include Voyeur's embedded widgets (http://voyeur.herme neuti.ca), and Ivanhoe (http://patacriticism .org/ivanhoe), which allows for community analysis of literary texts. While many text analysis applications exist, the exploration of the social potential of these tools is still only in its nascent stages.

This sketch is derived from and supplemented by the more wide-ranging materials presented in the two related appendices (published in Digital Humanities Quarterly). Pertinent characteristics shared by these tools, and the interactions and augmentations they facilitate, are that they are userrather than creator-driven, evolving rather than fixed, collective rather than individual, expansive rather than inclusive, and open source rather than proprietary and closed. ${ }^{18}$

\section{A Toolkit, Toward Modeling the 'Social' Edition}

The intersection of social media and the scholarly edition has given rise to tools that offer us new ways to work together, for our editions to work together, and for us to work with others. Despite calls like that of Stephen Nichols (2009) to 'dismantle the silo model of digital scholarship', many electronic scholarly editions, like print editions, continue to exist as self-contained units that do not encourage interaction with other resources, and they do not yet actively encourage or facilitate interaction among the communities of practice they serve or even among those who have the most knowledge to bring to bear. These tools, and others like them, can help remedy this. The 'social' edition grows from this, and the spirit of exhortations like that of Greg Crane, that '[w]e need to shift from lone editorials and monumental editions to editors... who coordinate contributions from many sources and oversee living editions' (2010). And, indeed, documented movement in this direction is already well underway with projects such as EEBO interactions, described as 'a social networking resource for Early English Books Online’, George Mason University's 'Crowdsourcing Documentary Transcription: An Open Source Tool', Transcribe Bentham, and more. ${ }^{19}$ These projects, and others similar, point to a growing need in the scholarly community to expand our knowledge communities using the social technologies at our disposal. Building on existing, expanding, and newlyemerging communities of practice in combination with the framework of social media, we can appropriately harness the power of specifically social tools, the majority of which move in some way towards combining digital social interaction with scholarly activities. 
This has a destabilizing effect; such tools facilitate a model of textual interaction and intervention that encourage us to see the scholarly text as a process rather than a product, and the initial, primary editor as a facilitator, rather than progenitor, of textual knowledge creation. The most conservative electronic scholarly editions or archives have used computation chiefly to 'describe and express print-, visual-, and audio-based material in tagged and searchable electronic form' (Schriebman et al. 2004, p. vi), in many ways mimicking interactive structures more suitable to possibilities of the print medium rather than the digital one; this teleological, codex-based model sees the editor as a single authority, a mediator between the text and the reader, where the editorial entity determines and shapes what is important to the reader, focuses the editorial and analytical lens, and ultimately exerts immense control over what the reader can engage. While it is nothing new to interrogate the 'single authoritative text' (see, among others, Shillingsburg, 1986, p. 16), and to consider the change in the structure of authority offered by the digital edition especially in relation to the dynamic nature of a digital text, ${ }^{20}$ the integration of social tools into the electronic scholarly edition pushes the boundaries of authority further, shifting power from a single editor, who shapes the reading of any given text, to a group of readers comprising a community whose interpretations themselves form a new method of making meaning out of the material. $^{21}$ In a 'social' edition, textual interpretation and interrelation are almost wholly created and managed by a community of users participating in collective and collaborative knowledge building using social technologies. Further, in expanding the community of practice-beyond a single editorial entity, to an academic group, and even beyond that group into citizen scholars-we cannot avoid challenging current notions of personal and institutional authority, and the systems by which they are sustained; ${ }^{22}$ the 'social' edition privileges a new kind of scholarly discourse network that eschews traditional, institutionally reinforced, hierarchical structures and relies, instead, upon those that are community-generated. ${ }^{23}$ Taken together, in this the 'social' edition appears to represent an extension of recent accepted and understood movements in editorial theory.

In brief, with the tools of social media at its center, the 'social' edition is process-driven, privileging interpretative changes based on the input of many readers; text is fluid, agency is collective, and many readers/editors, rather than a single editor, shape what is important and, thus, broaden the editorial lens as well as the breadth, depth, and scope of any edition produced in this way. A definitively 'social' edition employs new and emerging tools for interaction around such activities as transcription, bookmarking and bibliography-building, flagging and tagging, commenting and annotating, ${ }^{24}$ linking to contextual material (especially for names and integration of bibliographic information), glossary and other analytical functions, and all other pertinent activities that sit at the evolving intersection of social media and the electronic scholarly edition. Relying on dynamic knowledge building and privileging process over end result, this expansive structure offers new scholarly workflows and hermeneutical method that build, well, on what we already do.

This all said, the 'social' edition is not something-at least not 'yet' something-that we can clearly describe and typologize as readily as we now can the dynamic text, the hypertextual edition, and the dynamic edition; but the same could be said of the dynamic text, the hypertextual edition, and the dynamic edition at the times our community was busy experimenting with their precepts and building blocks, through theoretical engagement and prototypical experimentation. Regardless, the basic tenets of such a scholarly electronic edition are beyond first discernment, and indeed are becoming more readily visible almost daily through the evolution and adoption in our community of social media methods and its practices that we are increasingly, and more regularly, bringing to the electronic editions we produce.

Whatever it is that sits at the intersection of social media and the scholarly edition in electronic form-whatever the 'social' edition manifests itself as-as our community has known through our conjoint development of the dynamic text, the hypertextual edition, and the dynamic edition, the 'social' edition is something that we will articulate and 
define, through theory and functional prototyping, together.

\section{Acknowledgements}

The authors wish to express their gratitude for the support and feedback on the paper received by those in these forums, and from $L L C$ 's reviewers. In response to comments from the reviewers and the community about the nature of the material presented in this article, a companion to this article is published in Digital Humanities Quarterly, 'Pertinent Discussions Toward Modeling the Social Edition: Annotated Bibliographies' (http://www .digitalhumanities.org/dhq/vol/6/1/000111/000111 .html), consisting of two integral appendices, the first addressing pertinent issues to online reading and interaction (Koolen, Garnett), and the second an unpublished white paper on social networking drawn upon by several researchers in the area (Leitch).

\section{References}

Baumer, E., Sueyoshi, M., and Tomlinson, B. (2008). Exploring the Role of the Reader in the Activity of Blogging. Proceeding of the 26th ACM CHI Conference. New York: ACM.

Boyd, S. (2006). Are You Ready for Social Software? Stowe Boyd. http://stoweboyd.com/post/2325281845/are-youready-for-social-software (accessed 10 September 2012).

Bradley, J. (2004). Text Tools. In Schreibman, S., Siemens, R., and Unsworth, J. (eds), A Companion to Digital Humanities. Blackwell: Oxford.

Brown, J. S. and Adler, R. P. (2008). Minds on fire: open education, the long tail, and learning 2.0. Educause Review, 43(1): 16-32.

Bryant, J. (2002). The Fluid Text. A Theory of Revision and Editing for Book and Screen. Ann Arbor, MI: The University of Michigan Press.

Bush, V. (1945). As we may think. Atlantic Monthly, 176: 101-08.

Cadiz, J. J., Gupta, A., and Grudin, J. (2000). Using Web Annotations for Asynchronous Collaboration Around Documents. Proceedings of the ACM Conference on Computer Supported Cooperative Work. New York: ACM.
Cambridge, D., Soren, K., and Vicki, S. (2005). Community of Practice Design Guide: A Step-by-Step Guide for Designing \& Cultivating Communities of Practice in Higher Education. Educause http://www. educause.edu/ELI/CommunityofPracticeDesignGuide/ 160068. (accessed 18 July 2011).

Carmody, T. (2010). Copia, Social Reading App/Network/ Store, Comes Alive. Wired 18 November http://www. wired.com/gadgetlab/2010/11/copia-social-readingappnetworkstore-comes-alive/ (accessed 5 July 2011).

CIBER (University College, London). (2010). Social Media and Research Workflow. http://www.ucl.ac.uk/ infostudies/research/ciber/social-media-report.pdf (accessed 11 July 2011).

Cohen, D. J. (2008). Creating scholarly tools and resources for the digital ecosystem: building connections in the Zotero Project. First Monday, 13(8): http://first monday.org/htbin/cgiwrap/bin/ojs/index.php/fm/art icle/view/2233/2017 (accessed 13 July 2011).

Cohen, D. J. (2009). Engaging and Creating Virtual Communities. Proceedings of the Cultural Heritage Online Conference. Florence, Italy, pp. 28-32.

Cover, R. (1990). Encoding for textual parallels and critical apparatus. Text Encoding Initiative Working Paper, February 21, 1990.

Crane, G. (2010). Give us editors! Re-inventing the edition and re-thinking the humanities. The Shape of Things to Come. Charlottesville, VA, March 2010. http://shapeofthings.org/papers/ (accessed 30 April 2010).

Dahlström, M. (2004). How reproductive is a scholarly edition? Literary and Linguistic Computing, 19(1): 17-33.

Davis, J. R. and Huttenlocher, D. P. (1995). Shared Annotation for Cooperative Learning, The First International Conference on Computer Support for Collaborative Learning. Indiana University: Bloomington: L. Erlbaum Associates Inc., pp. 84-88.

Davis, P. (2010). Culture trumps technology: the UC Berkeley scholarly communication report. The Scholarly Kitchen 15 Feb 2010. http://scholarlykitchen. sspnet.org/2010/02/15/culture-trumps-technology/ (accessed 9 July 2011).

Estelles, E., del Moral, E., and González, F. (2010). Social bookmarking tools as facilitators of learning and research collaborative processes: the Diigo case. Interdisciplinary Journal of E-Learning and Learning Objects, 6: 175-91.

Faulhaber, C. B. (1991). Textual criticism in the 21st century. Romance Philology, 45: 123-48. 
Fernheimer, J. W., Litterio, L., and Hendler, J. (2011). Transdisciplinary ITexts and the future of web-scale collaboration. Journal of Business and Technical Communication, 25(3): 322-37.

Fitzpatrick, K. (2007). CommentPress: new (social) structures for new (networked) texts. Journal of Electronic Publishing, 10(3).

Fitzpatrick, K. (2009). Peer-to-peer review and the future of scholarly authority. Cinema Journal, 48(2): 124-29.

Fortier, P. A. (1991). Theory, methods and applications: some examples in French literature. Literary and Linguistic Computing, 6: 192-6.

Frye, N. (1991). Literary and Mechanical Models. In Lancashire, I. (ed.), Research in Humanities Computing 1: Select Papers from the ALLC/ACH Conference. Oxford: Clarendon Press, pp. 3-13.

Gabler, H. W. (2010). Theorizing the digital scholarly edition. Literature Compass, 7(2): 43-56.

Gielen, N. (2010). Handheld E-Book Readers and Scholarship: Report and Reader Survey http://www.humanitiese book.org/heb-whitepaper-3.html (accessed 2 October 2012).

Golder, S. and Huberman, B. A. (2006). Usage patterns of collaborative tagging systems. Journal of Information Science, 32(2): 198-208.

Greenberg, J. (2010). The Institution and the Crowd. Presentation http://www.slideshare.net/epistemographer/ the-institution-and-the-crowd (accessed 30 May 2010).

Greenhow, C. (2009). Social scholarship: applying social networking technologies to research practices. Knowledge Quest, 37(4): 42-47.

Guy, M. and Tonkin, E. (2006). Folksonomies: Tidying up Tags? D-Lib Magazine, 12(1): http://www.dlib.org/ dlib/january06/guy/01guy.html (accessed 11 July 2011).

Hammond, T., Hannay, T., Lund, B., and Scott, J. (2005). Social Bookmarking Tools (I): A General Review. D-Lib Magazine, 11(4): http://www.dlib.org/ dlib/april05/hammond/04hammond.html (accessed 14 July 2011).

Harley, D., Krzys Acord, S., Early-Novell, S., Lawrence, S., and Judson King, C. (2010). Assessing the Future Landscape of Scholarly Communication: An Exploration of Faculty Values and Needs in Seven Disciplines. Berkeley: University of California, Center for Studies in Higher Education.

Hendry, D. G., Jenkins, J. R., and McCarthy, J. F. (2006). Collaborative bibliography. Information Processing and Management, 42(3): 805-25.
Hoadley, C. M. and Kilner, P. G. (2005). Using Technology to Transform Communities of Practice into Knowledge-Building Communities. SIGGROUP Bulletin, 25(1): 31-40. (doi: 10.1145/1067699. 1067705) (accessed 30 April 2010).

Hornbæk, K. and Frokjær, E. (2001). Reading of Electronic Documents. Proceedings of the ACM CHI Conference. New York: ACM.

Howard, J. (2011). Social media lure academics frustrated by Journals. The Chronicle of Higher Education. http:// chronicle.com/article/Social-Media-Lure-Academics/ 126426/ (accessed 15 July 2011).

Hopkins, C. (2010). Mendeley Throws Open the Doors to Academic Data. ReadWriteWeb 29 April 2010 http:// www.readwriteweb.com/archives/mendeley_introduces _academic_catalog_search.php (accessed 15 July 2011).

Hunter, J., Cole, T., Sanderson, R., and Van de Sompel, H. (2010). The Open Annotation Collaboration: A Data Model to Support Sharing and Interoperability of Scholarly Annotations. Digital Humanities 2010: Conference Abstracts. London, UK: Office for Humanities Communication; Centre for Computing in the Humanities, pp. 175-78.

Inman, J. A., Reed, C., and Sands, P. (2004). Electronic Collaboration in the Humanities. Mahwah, NJ: Lawrence Erlbaum.

Irvine, D. (2006). Editing archives] archiving editions. Journal of Canadian Studies, 40(2): 183-211.

Kjellberg, S. (2010). I am a blogging researcher: motivations for blogging in a scholarly context. First Monday, 15(8).

Lancashire, D. I. (1989). Working with Texts. Paper delivered at the IBM Academic Computing Conference, Anaheim, CA.

Landow, G. P. (1999). Footnotes, Endnotes, and the Experience of Reading Hypertext. http://www.stg.brown .edu/projects/hypertext/landow/vp/reading.html (accessed 15. Nov. 1999; [URL may no longer be active]).

Lardinois, F. (2009). Reframe It Brings Facebook, Twitter, \& Web Luminaries to Its Annotation Tool. ReadWriteWeb, 30 March 2009 http://www.readwrite web.com/archives/reframe_integrates_facebook_and_ twitter.php (accessed 7 July 2011).

Lavagnino, J. (1995). Reading, scholarship, and hypertext editions. TEXT: Transactions of the Society for Textual Scholarship, 8: 109-24.

Lund, B., Hammond, T., Flack, M., and Hannay, T. Social Bookmarking Tools (II): A Case Study - 
Connotea. D-Lib Magazine, 11(4): http://www.dlib.org/ dlib/april05/lund/04lund.html 95 (accessed 14 July 2011).

Manovich, L. (2001). The Language of New Media. Cambridge: MIT Press.

Maron, N. L. and Smith, K. K. (2009). Current models of digital scholarly communication: results of an investigation conducted by Ithaka for the association of research libraries. Journal of Electronic Publishing, 12(1).

Marshall, C. C. (1997). Annotation: From Paper Books to the Digital Library. Proceedings of the Second ACM International Conference on Digital Libraries. Philadelphia: ACM, pp. 131-40.

Marshall, C. C. (2010). Reading and Writing the Electronic Book. New York: Morgan \& Claypool Publishers.

Mathes, A. (2004). Folksonomies - Cooperative Classification and Communication through Shared Metadata. http://www.adammathes.com/academic/computermediated-communication/folksonomies.html (accessed 9 March 2010).

MacFadyen, H. (2011). The reader's devices: the affordances of e-book readers. Dalhousie Journal of Interdisciplinary Management, 7(1).

McGann, J. (1997). The Rationale of HyperText. In Sutherland, K. (ed.), Electronic Text. Investigations in Method and Theory. Oxford: Clarendon Press, pp. 19-46.

McGann, J. (2001). Radiant Textuality: Literature after the World Wide Web. New York: Palgrave Macmillan.

McGann, J. (2002). Visible and invisible books: hermetic images in n-dimensional space. Literary and Linguistic Computing, 17(2): 61-75.

McGann, J. (2004). Marking Texts of Many Dimensions. In Schreibman, S., Siemens, R., and Unsworth, J. (eds), Companion to Digital Humanities. Oxford: Blackwell, pp. 198-217.

McGann, J. (2010). 'Introduction'. In McGann, J., Stauffer, A., Wheeles, D., and Pickard, M. (eds), Online Humanities Scholarship: The Shape of Things to Come. Houston: Rice University Press.

Mollet, A. (2011). Taking a Leaf Out of Poliakoff's Book: Embracing New Online Platforms Is Necessary for the Positive Survival of Academic Impact and Debate. Impact of Social Sciences, 9 June 2011 http:// blogs.lse.ac.uk/impactofsocialsciences/2011/06/09/ poliakoff-gearty-online-academic-impac/ (accessed 15 July 2011).

Mueller, M. (2005). The nameless Shakespeare. TEXT Technology, 14(1): 61-70.
Nelson, T. (1982). A new home for the mind? Datamation [PlugIn], 28(3): 168-80.

Neuman, M. (1991). The very pulse of the machine: three trends toward improvement in electronic versions of humanities texts. Computers and the Humanities, 25: 363-75.

Nikolov, R. (2009). Towards University 2.0: A Space Where Academic Education Meets Corporate Training. Arnhem, The Netherlands: IPROF-09: ICT Professionalism: A Global Challenge. http://hdl.handle.net/10506/136 (accessed 15 June 2011).

Nichols, S. (2009). Time to Change our Thinking: Dismantling the Silo Model of Digital Scholarship. http://www.ariadne.ac.uk/issue58/nichols/ (accessed May 10 2010).

O'Donnell, J. J. et al. (2010). Do You Like Your E-Reader? Six Takes from Academics. The Chronicle of Higher Education, 56(38). http://chronicle.com/article/Do-You-Like-Your-E-Reader-/65840/. ～(accessed 14 July 2011).

Ore, E. S. (2004). Monkey business, or what is an edition? Literary and Linguistic Computing, 19(1): $35-44$.

O'Reilly, T. (2005). What is Web 2.0? http://oreilly.com/ web2/archive/what-is-web-20.html (accessed 4 May 2010).

O'Reilly, T. and Battelle, J. (2009). Web Squared: Web 2.0 Five Years On. Web Summit. San Francisco. CA. http://www.web2summit.com/web2009/public/schedule/detail/10194 (accessed 10 May 2010).

Ovsiannikov, I. A., Arbib, M. A., and Mcneill, T. H. (1999). Annotation technology. International Journal of Human-Computer Studies, 50(4): 329-62.

Priem, J. and Costello, K. L. (2010). How and Why Scholars Cite on Twitter. Proceedings of the ASIS\&T Annual Meeting. Pittsburgh, PA, USA.

Procter, R., Williams, R., Stewart, J., Poschen, M., Snee, H., Voss, A., and Asgari-Targhi, M. (2010). Adoption and use of web 2.0 in scholarly communications. Philosophical Transactions of the Royal Society A, 368(1926): 4039-56.

Purdy, J. P. (2010). The changing space of research: web 2.0 and the integration of research and writing environments. Computers and Composition, 27(1): $48-58$.

Qayyum, M. A. (2008). Capturing the online academic reading process. Information Processing \& Management, 44(2): 581-95. 
Research Information Network. (2010). If You Build It, Will They Come? How Researchers Perceive and Use Web 2.0. http://rinarchive.jisc-collections.ac. uk/our-work/communicating-and-disseminatingresearch/use-and-relevance-web-20-researchers (accessed 9 July 2011).

Robinson, P. and Gabler, H. W. (eds), (2000). Introduction. Making texts for the next century. Literary and Linguistic Computing, 15(1)

Robinson, P. (2000). The one text and the many texts. Literary and Linguistic Computing, 15: 5-14.

Robinson, P. (2010). Electronic Editions for Everyone. In McCarty, W. (ed.), Text and Genre in Reconstruction. Effects of Digitization on Ideas, Behaviours, Products and Institutions. Cambridge: Open Book Publishers, pp. 145-63.

Rockwell, G. (2009). Short Guide to Evaluation of Digital Work. http://www.philosophi.ca/pmwiki.php/Main/ ShortGuideToEvaluationOfDigitalWork (accessed 20 June 2011).

Ross, C. L. (1996). The Electronic Text and the Death of the Critical Edition. In Finneran, R. J. (ed.), The Literary Text in the Digital Age. Ann Arbor: University of Michigan Press, pp. 225-32.

Ross, C., Terras, M., Warwick, C., and Welsh, A. (2011). Enabled backchannel: conference twitter use by digital humanists. Journal of Documentation, 67(2): 214-37.

Santo, A. and Lucas, C. (2009). Engaging academic and nonacademic communities through online scholarly work. Cinema Journal, 48(2): 129-38.

Scardamalia, M. and Bereiter, C. (1993). Technologies for knowledge-building discourse. Communications of the ACM, 36(5): 37-41.

Schreibman, S., Siemens, R., and Unsworth, J. (2004). The Digital Humanities and Humanities Computing: An Introduction. In Schreibman, S., Siemens, R., and Unsworth, J. (eds), A Companion to Digital Humanities. Oxford: Blackwell.

Shanahan, M.-C. (2010). Changing the meaning of peer-to-peer? Exploring online comment spaces as sites of negotiated expertise. JCOM: Journal of Science Communication, 9(1).

Shillingsburg, P. L. (1986). Scholarly Editing in the Computer Age. Athens: University of Georgia Press.

Shillingsburg, P. L. (1998). Resisting Texts: Authority and Submission in Constructions of Meaning. Ann Arbor, MI: University of Michigan Press.
Shillingsburg, P. L. (2006). From Gutenberg to Google: Electronic Representations of Literary Texts. Cambridge: Cambridge University Press.

Siemens, R. (2005). Text Analysis and the 'Dynamic' Edition? A Working Paper, Briefly Articulating Some Concerns with an Algorithmic Approach to the Electronic Scholarly Edition. CHWP, A 37/65 http:// journals.sfu.ca/chwp/index.php/chwp/article/ viewArticle/A.37/65 (accessed 12 May 2010).

Siemens, R., Leitch, C., Blake, A., Armstrong, K., and Willinsky, J. (2009). It may change my understanding of the field. Digital Humanities Quarterly, 3(4).

Siemens, R., Elkink, M., McColl, A. et al. (2010). Underpinnings of the Social Edition? A Narrative, 2004-9, for the Renaissance English Knowledgebase (REKn) and Professional Reading Environment (PReE) Projects. In McGann, J., Stauffer, A., Wheeles, D., and Pickard, M. (eds), Online Humanities Scholarship: The Shape of Things to Come. Houston: Rice University Press.

Sorrel, C. (2010). Kobo Update Adds Social Features, Nerd-Friendly Stats. Wired 10 December http://www .wired.com/gadgetlab/2010/12/kobo-update-adds-socialfeatures-nerd-friendly-stats/ (accessed 5 July 2011).

Tanselle, G.T. (1995). The Varieties of Scholarly Editing. In Greetham, D. C. (ed.), Scholarly Editing. New York: MLA, pp. 9-32.

Tashman, C. S. and Edwards, W. K. (2011). LiquidText: A Flexible, Multitouch Environment to Support Active Reading. Proceedings of the 2011 ACM CHI Conference, 3285-3294.

Terras, M. (2009). Crowdsourcing Manuscript Material. http://melissaterras.blogspot.com/2010/03/crowdsourcing-manuscript-material.html (accessed 2 March 2010).

The iPad for Professors: Evaluating a Productivity Tool After One Year. (2011). The Chronicle of Higher Education. http://chronicle.com/article/article-content/ 126885/ (accessed 14 July 2011).

Unsworth, J. (2000). Scholarly Primitives: What Methods Do Humanities Researchers Have in Common, and How Might Our Tools Reflect This? http://people.lis.illinois. edu/ unsworth/Kings.5-00/primitives.html (accessed 30 June 2009).

Unsworth, J. (2008). University 2.0. In The Tower and The Cloud. Higher Education in the Age of Cloud Computing. EDUCAUSE. pp. 227-37.

Vanderwall, T. (2007). Folksonomy. http://vanderwal.net/ folksonomy.html (accessed 29 April 2010). 
Wang, T. (2010). My New Academic Workflow With My Ipad, iAnnotate, Mendeley \& Dropbox. Cultural Bytes http://culturalbyt.es/post/1125482840/workflow (accessed 11 July 2011).

Watters, A. (2010). New Social E-Reading Platform Allows Real-Time Discussions, Right On the E-Book's Pages. ReadWriteWeb 22 November http://www.read writeweb.com/archives/new_social_e-reading_platform_allows_real-time_dis.php (accessed 5 July 2011).

Watters, A. (2011). Long Live Marginalia! ReadSocial Brings Annotations to Digital Literature. ReadWrite Web. 24 March http://www.readwriteweb.com/arch ives/love_live_marginalia_readsocial_brings_annota tions.php (accessed 5 July 2011).

Weisberg, M. (2011). Student attitudes and behaviors towards digital textbooks. Publishing Research Quarterly, 27(2): 188-96.

Wenger, E. (1998). Communities of practice: learning as a social system. Systems Thinker, 9(5): 1-10.

Wenger, E. (2006). Communities of Practice. http://www .ewenger.com/theory/ (accessed 29 Apr. 2010).

Winder, W. (1996). Texpert Systems. In Siemens, R. and Winder, W. (eds), Scholarly Discourse and Computing Technology: Perspectives on Pedagogy, Research, and Dissemination in the Humanities. Text Technology, 6(3): 159-66.

Wolfe, J. (2002). Annotation technologies: A software and research review. Computers and Composition, 19(4): 471-97.

Yang, S. J. H., Zhang, J., Su, A. Y. S., and Tsai, J. J. P. (2011). A collaborative multimedia annotation tool for enhancing knowledge sharing in CSCL. Interactive Learning Environments, 19(1): 45-62.

\section{Notes}

1 Each, and beyond, provide a far more complex, and more appropriately nuaced and detailed, treatment of essential issues and concepts of 'authority', 'text', 'work', and 'document' than we are able to in this more pragmatically oriented piece-recognition of which we are indebted to Peter Robinson, who was kind enough to comment on an earlier version of this article.

2 See also Robinson, (2000) 'The One Text and the Many Texts' and Robinson and Gabler, eds. (2000). 'Introduction'.

3 Lavagnino (1995) notes: 'it is striking how many proposals for hypertext editions fail to mention even the rather ordinary function of text searching ... mundane as it is, it is one of the most valuable things that can be done with electronic texts'.

4 See also Ross (1996), McGann (1997), and Landow (1999).

5 The exemplary Perseus Project, for example, comes very close to this ideal.

6 Such an edition embraces an electronic context and notion of inclusivity that Bush (1945), Frye (1991), Nelson (1995), and Winder (1996) have articulated; such an edition also requires that a significant amount of related scholarly material is available in electronic form.

7 See, for brief example and earlier state of the field, Bradley (2004).

8 Communication of results involves the electronic dissemination of, and electronically facilitated interaction about the product of, archival representation and critical inquiry, as well as the digitization of materials previously stored in other archival forms; Communication of results takes place via codified professional interaction, and is traditionally held to include all contributions to a discipline-centered body of knowledge-that is, all activities that are captured in the scholarly record associated with the shared pursuits of a particular field. Critical inquiry involves the application of algorithmically facilitated search, retrieval, and critical processes that, although originating in humanities-based work, have been demonstrated to have application far beyond; associated with critical theory, this area is typified by interpretive studies that assist in our intellectual and aesthetic understanding of humanistic works, and it involves the application (and applicability) of critical and interpretive tools and analytic algorithms on digitally represented texts and artifacts. Archival representation, in turn, involves the use of computer-assisted means to describe and express print-, visual-, and audio-based material in tagged and searchable electronic form; associated as it is with the critical methodologies that govern our representation of original artifacts, archival representation is chiefly bibliographical in nature and often involves the reproduction of primary materials such as in the preparation of an electronic edition or digital facsimile, and is centered in the context of our larger discussion on considerations of issues such as the modeling of objects and processes, the impact of social theories of text on the role and goal of the editor. Ideally, object modeling for archival representation should simulate the original object-artifact, both in terms of basic representation (e.g. a scanned image of a printed page) and functionality (such as the ability to 'turn' or otherwise 'physically' manipulate the 
page). However, object modeling need not simply be limited to simulating the original. Although 'a play script is a poor substitute for a live performance', Martin Mueller has shown that 'however paltry a surrogate the printed text may be, for some purposes it is superior to the "original" that it replaces' $(2005$, p. 61). The next level of simulation beyond the printed surrogate, namely the 'digital surrogate', would similarly offer further enhancements to the original. These enhancements might include greater flexibility in the basic representation of the object (such as magnification and otherwise altering its appearance) or its functionality (such as fast and accurate search functions, embedded multimedia, etc).. Archival representation might then involve modeling the process of interaction between the user and the object-artifact. Simulating the process affords a better understanding of the relationships between the object and the user, particularly as that relationship reveals the user's disciplinary practicesdiscovering, annotating, comparing, referring, sampling, illustrating, representing.

9 From McGann we adopt the following critical and theoretical points: (1) the recognition that scholars read what Barthes calls the 'plural text' by reading across dimensions and (2) a concern that 'digitization . . . situates the critical agent outside the field to be mapped and re-displayed' (McGann, 2004, p. 206). McGann identifies a text's dimensions as 'linguistic' (semantic and grammatical markers), 'graphical/auditional' (textual materiality), 'documentary' (descriptors tied to specific object: bibliography, paleography, provenance), 'rhetorical' (categorization, ordering, arrangement), 'semiotic' ('patterned relationships throughout the textual system' (p. 214), and 'social' (production and reception history) (p. 213-15). These codes and dimensions are neither prescriptive nor exhaustive but provide opportunities to read a text from different perspectives.

Of the six dimensions, digital texts to date have been most successful in mediating the first four but have had more limited success with the semiotic and social dimensions. This is not to say that current edition models do not address the semiotic dimension, which McGann describes as the 'patterned relationships throughout the textual system' (p. 214) or include information about a text's production and reception history. In current models of digital editions, the problem is that we are not capturing the fluid state of a text's production and reception as it is remediated online. Where we see an opportunity to intervene is in extending these dimensions to include an ongoing interrogation of the social and semiotic life of the text. McGann's delineation of
'N-dimensions' offers a promising shift in paradigm, a shift, we would suggest, that points us directly to the construction of a specifically 'social' edition that takes this fluidity into account. McGann writes that,

Traditional textual conditions facilitate textual study at an inner standing point because all the activities can be carried out - can be represented — in the same field space, typically, in a bibliographical field. Subject and object meet and interact in the same dimensional space - a situation that gets reified for us when we read books or write about them. Digital operations, however, introduce a new and more abstract space of relations into the study-field of textuality. This abstract space brings the possibility of new and in certain respects greater analytic power to the study of traditional texts. (McGann, 2004, p. 205)

His proposed model affords a broadening of our conceptual understanding of the layers of reading; or, reading across dimensions.

10 Wenger (2006); see also Wenger (1998), Cambridge et al. (2005), and Cohen (2009).

11 Specific instances of this have become almost too numerous to list. For one example, see Crane (2010). For more general discussion of this, see Santo and Lucas (2009) and, on the very closely related topic of social media's role in expanding the work of academe into its larger public context, see Brown and Adler (2008), Unsworth (2008), Nikolov (2009), and Mollet (2011). For background and expansion, see 'Background and History' in Leitch's overview and bibliography in the second appendix, published in Digital Humanities Quarterly.

12 For some, this might raise concerns related to qualitative assurance; in this vein, see among many others Fitzpatrick (2009). At the moment, the most useful discussions are taking place at conferences and in the blogosphere.

13 Here, too, we need to broaden our view of where this type of software is most typically used, beyond standard laptop and desktop computers and onto dedicated reading devices of various kinds, particularly e-readers, plus other computational devices that we use to access web-based information. With respect to this, and to e-readers in the academic workflow, see Gielen (2010), Marshall (2010), O’Donnell et al. (2010), 'The iPad for Professors' (2011), MacFadyen (2011), and Wang (2010).

14 For collaborative learning, see among others Scardamalia and Bereiter (1993), Davis and 
Huttenlocher (1995). For collaborative reading, see among others Hornbæk and Frokjær (2001), Qayyum (2008), Carmody (2010), Sorrel (2010), Watters (2010), Tashman and Edwards (2011), and Weisberg (2011), as well as Baumer et al. (2008), Purdy (2010), Shanahan (2010), and Weisberg (2011).

15 For these, and beyond, see 'Identity, Privacy \& Trust' in the second appendix, published in Digital Humanities Quarterly.

16 For general treatments of the use of social media aspects of higher education and research practice, see among others Greenhow (2009), Maron and Smith (2009), CIBER (2010), Davis (2010), Harley (2010), Procter et al. (2010), and Research Information Network (2010). For libraries see 'Education \& Libraries' in the second appendix, published in Digital Humanities Quarterly.

17 For discussion beyond those already cited above, see 'Collaboration' in the second appendix, published in Digital Humanities Quarterly.

18 For a more detailed discussion of Web 2.0, see O'Reilly (2005), and O'Reilly and Battelle (2009).

19 See Melissa Terras' list of collaborative projects (2009). The George Mason project is described as 'an open source tool that would allow scholars to contribute document transcriptions and research notes to digital archival projects, using the Papers of the War Department as a test case'.

20 See Shillingsburg $(1998,2006)$ and Dahlström (2004). Dahlström writes, 'the web edition turns into a large resource archive and editorial laboratory, and even more often into a more or less temporary interface to a changing, dynamic digital archive' (p. 18).

21 We recognize that there is considerable and valid concern registered around the notion of 'community interpretation'.

In doing so, we do not question authority in terms of the multiple variants of a manuscript, for example, but more broadly ask how readers have collective power to make meaning from multiple texts. With an understanding that an edition performs 'the considered act of reproducing or altering texts' (Tanselle, 1995 , p. 10), the socialized text moves us towards a broader understanding of the text itself as an authorial and social entity; however, the traditional scholarly edition (whether in a print or digital medium) nonetheless follows a 'top-down' model that, in its interpretative and representational aspects, is static once published. Digital humanists have already questioned the genre of the database (Manovich, 2001), and spoken to the importance of providing both digital facsimiles and encoded source-texts (Ore, 2004, p. 35). The discussion that follows on the social 'edition' naturally extends to the construction of a social 'archive' (Irvine, 2006, p. 184). Irvine has offered a productive way of understanding the socialized text:

Instead of superseding current critical editionswhether in print or online-or privileging one version or editorial practice over others, these digital archives could potentially enfold any number of critical and non-critical editions into an indexed network in which each edition is experienced as a socialized text-that is, social objects embedded in an apparatus that bears witness to the history of the edition's production, trans- mission, and reception. (pp. 202-03)

To construct a social edition, we must rely on earlier theories of editorial practice and disciplinary conventions to determine our source text and ultimately the digital representation of that text (Shillingsburg, 1986, Tanselle, 1995, McGann, 1997, 2001, 2002, 2004, 2010). But as a further step in socialization, the paratext, rather than the text, becomes the focal point.

22 The single-authored monograph has become both the gold ring and bete noire for those seeking tenure in the humanities, and has seen much (re)consideration in recent times. More to the point: with its lack of a single, authoritative editor, the social edition may seem to some to be a freewheeling invitation to early-career stasis. It is important that while we are imagining the form the social edition will take that we also imagine how it will be received by our institutions. Work in discussion by the Modern Language Association's Committee on Information Technology is heartening. Currently, their 'Short Guide to Evaluation of Digital Work' includes a section on best practices in 'enrichment' that reads '[i]n some cases enrichment can take the form of significant new scholarship organized as interpretative commentary or essay trajectories through the material. . . . Such interpretative curation is itself scholarly work that can be evaluated as a form of exhibit or essay' (Rockwell, 2009). The work of the editor of the social edition is to make this kind of curation possible for members of the community of practice to undertake. By acting as a facilitator for community enrichment, the scholar or scholars heading up a social edition project must demonstrate considerable editorial skill in identifying possible avenues for interpretation and technological sensitivity in finding ways to make this kind of editing work. 
23 See Fitzpatrick (2007):

Scholars operate in a range of conversations, from classroom conversations with students to conference conversations with colleagues; scholars need to have available to them not simply the library model of texts circulating amongst individual readers but also the coffee house model of public reading and debate. This interconnection of individual nodes into a collective fabric is, of course, the strength of the network, which not only physically binds individual machines but also has the ability to bring together the users of those machines, at their separate workstations, into one communal whole.

24 Collaborative annotation offers a particularly rich toolkit for the humanities scholar, and seems a prudent place to begin to envision the interactivity inherent within the social edition. 